\title{
Void Formation and Strain-Induced Martensitic Transformation in TRIP780 Steel Sheet Submitted to Uniaxial Tensile Loading
}

\author{
Bárbara Corrêa Castanheira ${ }^{a}$, Luciano Pessanha Moreira ${ }^{a}$, Gabriel Onofre do Nascimento ${ }^{b}$, \\ Rafael Oliveira Santos ${ }^{a, c}\left({ }^{\circledR}\right.$, Gabriel Augusto de Avila Santiago ${ }^{a}$, Isabela Santana de Oliveirad, \\ Fabiane Roberta Freitas da Silva ${ }^{e}$ \\ ${ }^{a}$ Programa de Pós-graduação em Engenharia Metalúrgica, Universidade Federal Fluminense, Av. dos \\ Trabalhadores, 420, 27255-125, Volta Redonda, RJ, Brasil

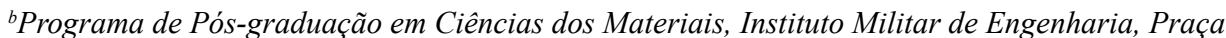 \\ General Tibúrcio, 80, 22290-270, Urca, Rio de Janeiro, RJ, Brasil \\ ${ }^{c}$ Centro Federal de Educação Tecnológica Celso Suckow da Fonseca, Campus Angra dos Reis, Rua do \\ Areal, 522, 23953-030, Angra dos Reis, RJ, Brasil \\ ${ }^{d}$ Departamento de Engenharia Mecânica, Universidade Federal Fluminense, Av. dos Trabalhadores, \\ 420, 27255-125, Volta Redonda, RJ, Brasil \\ ${ }^{e}$ Departamento de Engenharia Metalúrgica e de Materiais, Universidade Federal Fluminense, Av. dos \\ Trabalhadores, 420, 27255-125, Volta Redonda, RJ, Brasil
}

Received: March 19, 2019; Revised: July 13, 2019; Accepted: December 5, 2019.

This work aimed to analyze the damage behavior of cold rolled TRIP780 steel sheet submitted to interrupted uniaxial tensile tests performed along the rolling direction. The formation of voids is investigated as a function of the straining level using digital image analysis of scanning electron micrographs to obtain the measures of void density, void area fraction, void aspect ratio and mean void size. The volume fractions of both ferrite/martensite and retained austenite constituents were obtained from X-ray diffraction measurements. An abruptly decrease of retained austenite was observed at early stages of deformation followed by a slow saturation. The resulting strain-induced martensite is responsible for improving the formability of the TRIP780 as observed by instantaneous strain-hardening exponent. In the lower strain range, growth and coalescence of existing microvoids prevailed at both in-plane directions whereas nucleation of microvoids was also observed along the loading direction. Conversely, nucleation prevailed at the transverse direction in the intermediate strain range whereas growth and coalescence were predominant aligned to the loading direction. At larger strain levels, growth and coalescence of microvoids prevailed at both directions. The microvoids were initially found around inclusions and at the interface of ferrite-martensite phases and lastly also at the ferrite matrix.

Keywords: Strain-induced martensite, retained austenite, void formation, uniaxial tensile, TRIP780 steel.

\section{Introduction}

Nowadays, advanced high-strength steels (AHSS) for the automotive industry are grouped in three generations ${ }^{1}$ for applications demanding enhanced crashworthiness performance in frontal and lateral collisions and lightweight structures components with lower production costs aiming at substantially increasing the fuel efficiency and, thus, reducing the greenhouse gas emissions. Among the $1^{\text {st }}$ and $2^{\text {nd }}$ generations of AHSS, TRIP (Transformation Induced Plasticity)-assisted steels resulting from the transformation effects of the retained austenite metastable grains during deformation became an efficient cost-effective option over some concurrent steels as, for instance, Dual-Phase (DP) from the $1^{\text {st }}$ generation of AHSS and TWIP (Twinning-induced plasticity) steels with high-Mn content and austenite microstructure from the $2^{\text {nd }}$ generation of AHSS. The $3^{\text {rd }}$ generation of AHSS, combining the TRIP effects from the $1^{\text {st }}$ generation AHSS grades with low alloying costs in comparison to the $2^{\text {nd }}$ generation, is

*e-mail: luciano.moreira@metal.eeimvr.uff.br. processed via novel thermomechanical processing routes using new chemical compositions to result in microstructures of medium-Mn (TRIP+TWIP) $)^{2}$, quenching and partitioning $(\mathrm{Q} \& \mathrm{P})^{3}$ and as well as carbide-free bainitic $(\mathrm{CBF})^{4}$ steels. Currently, the emerging $3^{\text {rd }}$ generation of AHSS grades is receiving much attention from the global industry and academic research groups to determine industrial operational windows along with economic production costs targeting to their future commercialization scale ${ }^{5}$.

TRIP steels sheets from the $1^{\text {st }}$ generation of AHSS for automotive applications ${ }^{6}$, according to the available commercial grades and standard nomenclature TRIP YS/ UTS (Minimum Yield Stress in MPa/Minimum Ultimate Yield Strength in MPa), are used to manufacture frame rails and rail reinforcements (TRIP 350/600), side rail and crash box (TRIP 400/700), dash panel and roof rails (TRIP 450/800) and B-pillar upper, roof rail, engine cradle, front and rear rails and seat frame (TRIP 600/980). These TRIP-assisted steels usually have a low content of allowing elements resulting in a multiphase microstructure commonly 
composed by a ferrite matrix, islands of bainite, martensite and, in particular, the retained metastable austenite which, during the plastic deformation might be partially or fully transformed into martensite.

The strain-induced martensitic transformation (SIMT) effects, resulting from the retained austenite in the TRIPassisted steels grades of both $1^{\text {st }}$ and $3^{\text {rd }}$ generations of AHSS, are the main responsible for improving the formability of these AHSS steels in sheet metal forming processes by increasing the uniform elongation and, thus, delaying the necking onset. The SIMT is dependent on the initial volume fraction of retained austenite and its stability ${ }^{7}$, stress triaxiality ${ }^{8,9}$, strain-rate and temperature ${ }^{8,9}$. Bearing in mind the role of the complex characteristics of the multiphase TRIP-assisted steels in both mechanical properties and damage that control the ultimate failure in sheet metal forming, this work aimed at evaluating the volume fraction of retained austenite and void formation as a function of plastic strain of a cold rolled zinc coated TRIP780 steel sheet submitted to interrupted uniaxial tensile tests. Samples from both as-received and pre-strained conditions under uniaxial tensile test loading were employed to determine the measures of void density, void area fraction, void aspect ratio and mean void size using scanning electron microscope digital images and $\mathrm{X}$-ray diffraction measurements to quantify the retained austenite evolution as a function of the imposed strains.

\section{Materials and Methods}

\subsection{Materials and mechanical testing}

A transformation-induced-plasticity (TRIP) steel 780 grade supplied by ArcelorMittal Vega (Brazil) as cold rolled zinc coated sheet with $1.5 \mathrm{~mm}$ nominal thickness is analyzed by means of room temperature interrupted uniaxial tensile tests, microstructural characterization, void formation (VF) and X-ray diffraction (XRD) measurements of deformed specimens to investigate the strain-induced martensite transformation (SIMT) of the initial retained austenite. The investigated material is an alternative to the standard CMnSi composition TRIP-aided steel, see the chemical composition listed in Table 1, with partial replacement of $\mathrm{Si}$ by both $\mathrm{Al}$ and $\mathrm{P}^{10}$. This composition results in low Carbon TRIP steels that are very attractive to be produced via intercritical annealing in conventional continuous galvanizing lines owing to the $\mathrm{Al}$ alloying which increases the bainitic transformation kinetics ${ }^{11}$.
Rectangular samples cut along the sheet rolling direction and machined by NC milling tensile specimens with geometry dimensions depicted in Figure 1, as per JIS Z 2201 standard $^{12}$. The uniaxial tensile tests were performed in a screw-driven universal testing machine EMIC equipped with a load cell of $300 \mathrm{kN}$ and a contact-type extensometer with $50 \mathrm{~mm}$ gauge length. All tests were conducted at room temperature with a constant cross-head speed of 1 $\mathrm{mm} / \mathrm{min}$. The uniaxial tensile specimens were deformed at four increasing straining levels defined as a function of the imposed longitudinal total true-strain by $5,10,15$ and $18 \%$ to analyze both void formation (VF) and straininduced martensite transformation (SIMT) as a function of the imposed strain. For each straining level, two replicas were tested in a total of eight uniaxial tensile specimens. After the mechanical testing campaign, the specimens were carefully cut, with the help of the Buehler IsoMet 1000 precision cutter, along the parallel and transverse crosssections with respect to the specimen length as depicted in Figure 1(b). One sample from the as-received condition was also cut and analyzed in both rolling and transverse sheet directions.

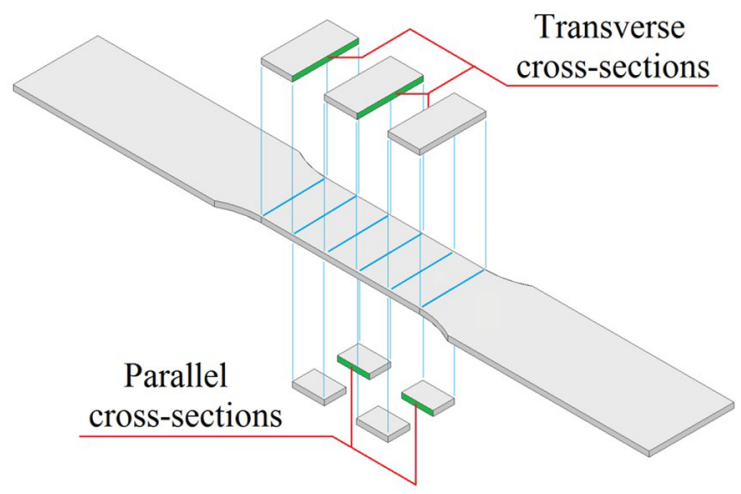

(b)

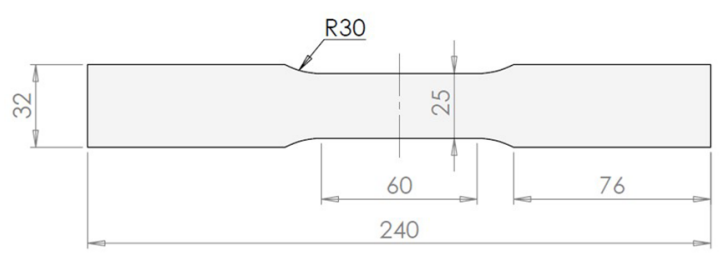

(a)

Figure 1. Uniaxial tensile test specimen according to JIS standard: (a) geometry and dimensions and (b) schematic view indicating the cross-sections used in the microvoid and XRD analyses.

Table 1. Chemical composition (mass \%) of the TRIP steel. Provided by ArcelorMittal Vega.

\begin{tabular}{lccccccc}
\hline $\mathrm{C}$ & $\mathrm{Mn}$ & $\mathrm{P}$ & $\mathrm{S}$ & $\mathrm{Si}$ & $\mathrm{Nb}$ & $\mathrm{B}$ & $\mathrm{Al}$ \\
0.22 & 1.89 & 0.017 & 0.0017 & 0.27 & 0.018 & 0.0003 & 1.54 \\
$\mathrm{Cr}$ & $\mathrm{Sn}$ & $\mathrm{Mo}$ & $\mathrm{Ti}$ & $\mathrm{Ni}$ & $\mathrm{Sn}$ & $\mathrm{V}$ & $\mathrm{Sb}$ \\
0.18 & 0.003 & 0.005 & 0.004 & 0.009 & 0.003 & 0.003 & 0.003 \\
\hline
\end{tabular}




\subsection{Microstructural characterization and void analysis}

The preparation of the samples was done according to standard metallographic procedures by firstly polishing with alumina $0.05 \mu \mathrm{m}$ and secondly by attacking with LePera reagent for quantitative analysis using the optical microscope Olympus BX51M model and lastly using Nital 3\% etchant for qualitative analysis by scanning electron microscopy (SEM) technique using the Carl Zeiss EVO MA10 microscope model. The volume fractions of the phases were quantified from forty micrographs taken at random locations on the as-received sample condition with the help of the Image Pro-Plus software, as per ASTM E562 ${ }^{13}$ standard.

For micro-void analysis, samples taken from the crosssections shown in Figure 1(b) were prepared with dimensions of $1.5 \mathrm{~mm}$ (ND - Normal Direction) x $10 \mathrm{~mm}$ (RD - Rolling Direction) and $1.5 \mathrm{~mm}$ (ND - Normal Direction) x $25 \mathrm{~mm}$ (TD - Transverse Direction). Then, polished with colloidal silica suspension of $0.02 \mu \mathrm{m}$. For both as-received and deformed conditions, the samples were analyzed without etching on the Carl Zeiss EVO MA10 scanning electron microscope using a magnification of $1,000 \mathrm{X}$. The microvoids of both parallel and transverse cross-sections were analyzed from twenty-five digital images of both as-received and tested conditions. The "Analyze Particles" function of the Image-J software was used in the quantitative analysis of micro-voids to determine the measures of void density, void area fraction, void aspect ratio and mean void size according to the definitions given in Table 2, as detailed elsewhere ${ }^{14}$.

Table 2. Definitions of microvoids measures and abbreviations.

\begin{tabular}{lcc}
\hline Void Density & VD & $\begin{array}{c}\text { Number of voids/Total area } \\
(\mathrm{x} 1,000)\end{array}$ \\
Void Area Fraction & VAF & $\begin{array}{c}\sum \text { Void area/Total area } \\
(\mathrm{x} \mathrm{100 \% )}\end{array}$ \\
Void Aspect Ratio & VAR & $\begin{array}{c}\text { Mean void length/Mean void } \\
\text { width }(-)\end{array}$ \\
Mean Void Size & MVS & $\sum$ Void area/Void number $\left(\mu \mathrm{m}^{2}\right)$ \\
\hline
\end{tabular}

\subsection{X-ray diffraction (XRD) measurements}

The preparation of the samples for the X-ray diffraction (XRD) measurements followed the same procedure adopted in the micro-void analysis. The samples were taken parallel to the sheet plane with dimensions of $10 \mathrm{~mm}$ (RD - Rolling Direction) x $25 \mathrm{~mm}$ (TD-Transverse Direction), were analyzed without etching in the X-ray diffractometer Panalytical X'Pert $\mathrm{PRO}$ with a $\mathrm{Cu}$ tube and $\mathrm{K}$-alpha radiation operated at 40 $\mathrm{kV}$ and $40 \mathrm{~mA}$ using a scanning range from $40^{\circ}$ to $110^{\circ}$ with a scan speed of $0.03 \%$.

The volume fraction of both ferrite and martensite constituents was determined by the integration of the intensity of ferrite-martensite $\left(\alpha / \alpha^{\prime}\right)$ peaks $(110)_{\alpha / \alpha,},(200)_{\alpha / \alpha},(211)_{\alpha / \alpha}$, and $(220)_{\alpha / \alpha}$ whereas the retained austenite (RA) volume fraction was calculated from the integration of the austenite $(\gamma)$ peaks $(111)_{\gamma},(200)_{\gamma},(220)_{\gamma},(311)_{\gamma}$ and $(222)_{\gamma}$. The XRD data analysis was performed in the software PowderCell 2.4 using the Rietveld refinement function.

\section{Results and Discussion}

\subsection{As-received Microstructure and Inclusions Analysis}

The microstructure of the TRIP780 steel analyzed by light optical microscopy (LOM) revealed with LePera etchant, shown in Figure 2(a), with the martensite and retained austenite constituents (M/RA) in bright color whereas the ferrite $(\mathrm{F})$ matrix and bainite (B) are shown in bright and dark brown, respectively. The martensite and retained austenite (M/RA) constituents are distributed within the ferrite grains in the form of isolated islands. The bainite phase (B), resulting from the isothermal temperature holding time, presented a lenticular shape located around the M/RA constituents. The corresponding microstructure processed by digital image analysis, depicted in Figure 2(b), is composed of colored areas in green for ferrite (F), blue for martensite- retained austenite (M/RA) and bainite (B) in red. From image processing, the quantitative analysis provided the volume fractions of $67.9 \pm 1.0 \%$ for ferrite $(F)$, $22.6 \pm 0.9 \%$ for bainite (B) and $9.3 \pm 0.3 \%$ for martensiteretained austenite (M/RA) constituents. Figure 3 shows a micrograph from the as-received condition of the TRIP780 steel sheet analyzed by the scanning electron microscope at the transverse cross-section (ND - Normal Direction and TD - Transverse Direction). From the morphology of the grains, it is not possible to distinguish the existing phases as, for instance, martensite and retained austenite and, thus, henceforth, martensite and retained austenite are referred to $\mathrm{M} / \mathrm{RA}$ constituents.

The inclusions in the as-received condition of the TRIP780 steel sheet were analyzed according to ASTM E45-13 ${ }^{15}$ standard. In the quantitative analysis, the samples were not etched and analyzed using the Nikon optical microscopy Eclipse LV150 with the help of polarized light. The inclusions in the investigated TRIP780 steel sheet are classified as being composed of thin B-Alumina type with a severity level of 0.5 as per ASTM E45-13 ${ }^{15}$. Figure 4(a) shows the characteristic inclusions (I) that can be found at the ferrite $(\mathrm{F})$ matrix surrounded by hard phases with the incidence of some initial microvoids (V). For qualitative analysis, the samples were polished and etched with Nital 3\% solution for 15 seconds and identified in the Carl Zeiss EVO MA10 scanning electron microscope (SEM). Also, energydispersive X-ray spectroscopy (EDS) element analysis was conducted in samples from the as-received state, prepared according to standard metallographic procedures, in order to identify the inclusions content using the Carl Zeiss EVO 


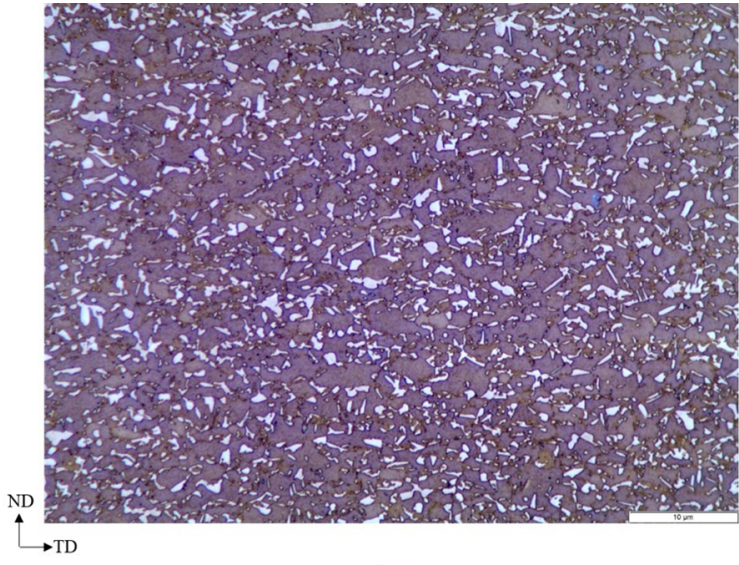

(a)

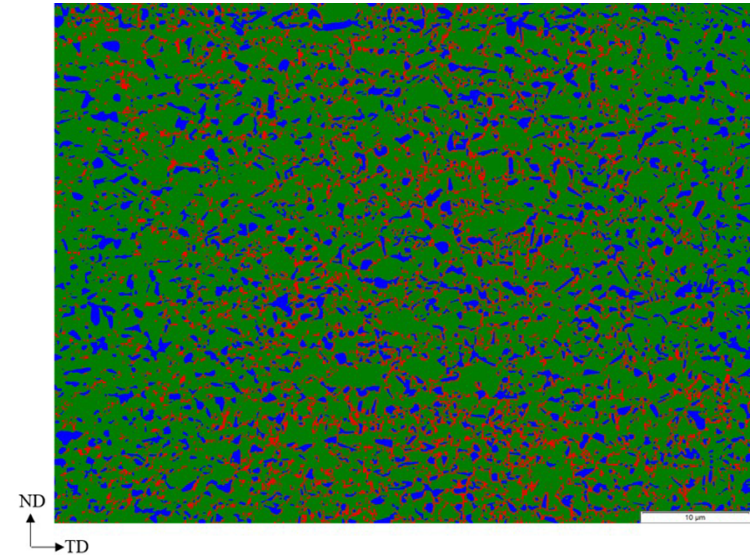

(b)

Figure 2. TRIP780 as-received microstructures observed employing light optical microscopy: (a) revealed with LePera etchant (1000X) and (b) from color digital image processing (1000X). (ND - Normal Direction and TD - Transverse Direction).

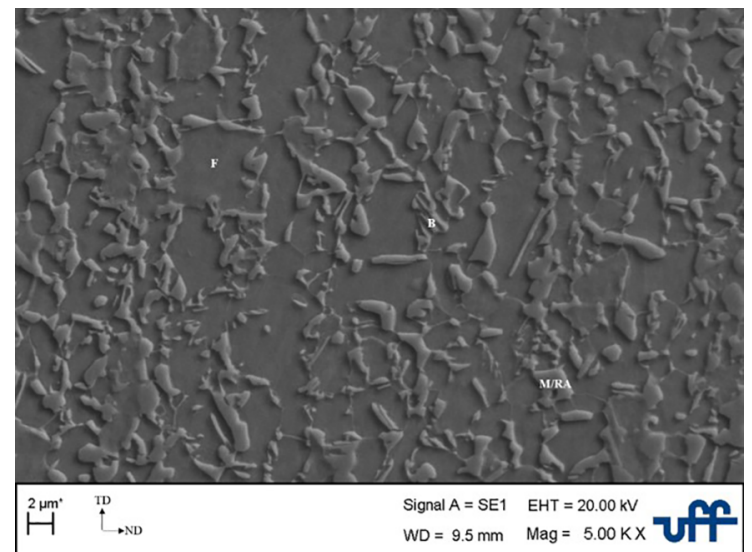

Figure 3. TRIP780 steel as-received microstructure observed by scanning electron microscopy (ND - Normal Direction and TD Transverse Direction).
MA10 scanning electron microscope. From EDS element analysis, see the representative results shown in Figure 4(b), in which the principal concentrations (normalized wt\%) revealed are of O (13.5\%), C (13.1\%), Al (11.5\%) and $\mathrm{S}(7.8 \%)$, thus, indicating the presence of non-metallic inclusions of aluminum-oxide, carbides, and sulfides.

\subsection{XRD Analysis}

The X-ray diffractograms of the TRIP780 steel sheet determined from the as-received state and interrupted uniaxial tensile tests at increasing pre-straining levels are shown in Figure 5. The intensities of the austenite peaks $(111)_{\gamma},(200)_{\gamma}$, $(220)_{\gamma},(311)_{\gamma}$ and $(222)_{\gamma}$ decreased with the imposed uniaxial strain. It should be noted that only the austenite $(\gamma)$ and ferrite plus martensite $\left(\alpha / \alpha^{\prime}\right)$ volume fractions could be determined

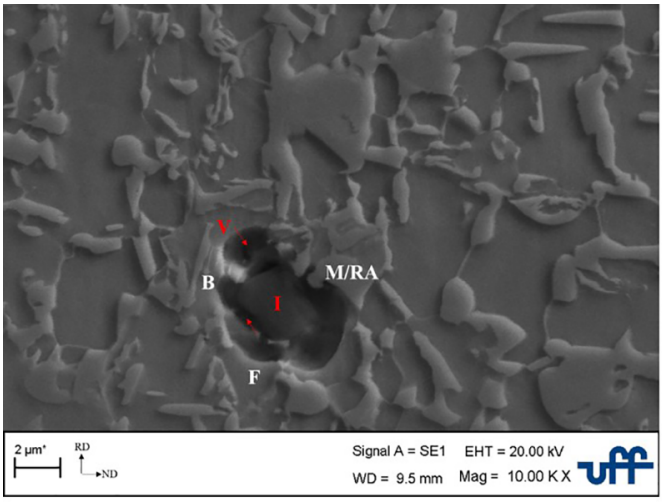

(a)

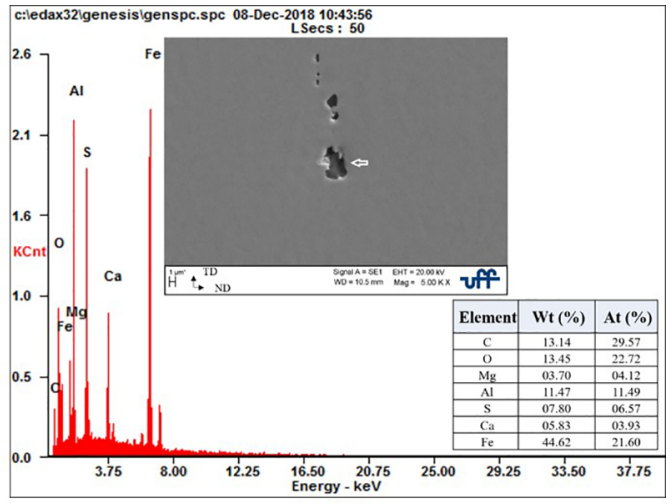

(b)

Figure 4. Inclusions aspects of the TRIP780 steel determined from the as-received condition: (a) scanning electron microscopy image (10000x) with an inclusion (I) at the ferrite (F) matrix surrounded by hard phases of bainite (B) and martensite/retained austenite (M/ RA) constituents and (b) energy-dispersive X-ray spectroscopy results of the inclusion indicated by an arrow (ND - Normal Direction, RD - Rolling Direction and TD - Transverse Direction). 
from the integration of the corresponding intensity peaks since the $\alpha$ '-martensite peaks cannot be resolved from the $\alpha$-iron bcc (110), (200) (211) and (220) peaks and, thus, the calculated volume fractions from the integration of the intensity peaks provided $\mathrm{V}_{\gamma}+\mathrm{V}_{\alpha / \alpha^{\prime}}=1$. Accordingly, the volume fraction of RA \% (respectively $\mathrm{F} / \mathrm{M} \%$ ) determined for the as-received condition is $7.9 \%(92.1 \%)$ whereas the RA volume fractions obtained from deformed samples are equal to $6.0 \pm 0.1 \%(94.0 \pm 0.1 \%), 3.8 \pm 0.1 \%(96.2 \pm 0.1 \%)$, $3.1 \pm 0.4 \%(96.9 \pm 0.4 \%)$ and $2.6 \pm 0.3 \%(97.4 \pm 0.3 \%)$ which correspond to the pre-straining levels of $5 \%, 10 \%, 15 \%$ and $18 \%$, respectively. Figure 6 (a) depicts the evolution of the averaged retained austenite volume fraction of the TRIP780 steel with the imposed prestraining level under uniaxial tensile loading conditions along with the initial volume fraction obtained from the as-received state. A rapid decrease in the RA occurred from the early deformation stage up to an intermediate straining level of about $10 \%$ followed by a slow saturation up to $18 \%$. Similar RA results have also been obtained with the help of X-ray and neutron diffraction measurements to determine the volume fraction and mass fraction of the retained austenite for $\mathrm{CMnSi}^{16}$ and $\mathrm{CMnAl}^{17}$ TRIP-aided steels submitted to uniaxial tension loading, respectively. Figure 6(b) shows the corresponding volume fraction of the transformed martensite $\left(\alpha^{\prime}\right)$ calculated from both the initial and average RA volume fractions. Considering the uniaxial tensile testing performed at a room temperature of $25^{\circ} \mathrm{C}$ using a nominal strain-rate given by 1 $(\mathrm{mm} / \mathrm{min}) / 60(\mathrm{~mm}) \sim 2.8 \times 10^{-4} \mathrm{~s}^{-1}$ which is relatively low and, thus, one can assume a quasi-isothermal deformation process wherein the RA is more unstable, the SIMT kinetics is clearly pronounced up to intermediate strains, as indicated in Figure 6(b). Magnetic measurements performed in larger samples with the help of a commercial feritscope ${ }^{8}$, provided the same behavior of the martensite transformation kinetics obtained for a commercial TRIP780 steel sheet evaluated at 25,60 and $100^{\circ} \mathrm{C}$ in uniaxial tension, equibiaxial tension, plane-strain, simple shear and in-plane uniaxial compression.

\subsection{Mechanical behavior}

The true-stress and true-strain results of the TRIP780 steel sheet obtained from one replica set of the uniaxial tensile tests performed at increasing interrupted straining levels are compared in Figure 7(a) with the data of a continuous tensile test (CT) up to fracture with a smaller constant cross-head speed of $0.1 \mathrm{~mm} / \mathrm{min}$ to prevent damage of the contact-type extensometer. The average mechanical properties from three uniaxial tensile tests at $0.1 \mathrm{~mm} / \mathrm{min}$ provided the yield stress of $455 \mathrm{MPa}$ and yield strength of $994 \mathrm{MPa}$ along with a true uniform strain of 0.22 . From this plot, it is possible to observe a continuous yielding of the TRIP780 steel sheet and also a strain-rate sensitivity effect which, in turn, is not the subject of the present investigation. Both higher uniform elongation and yield strength are favored by the SIMT effects that are

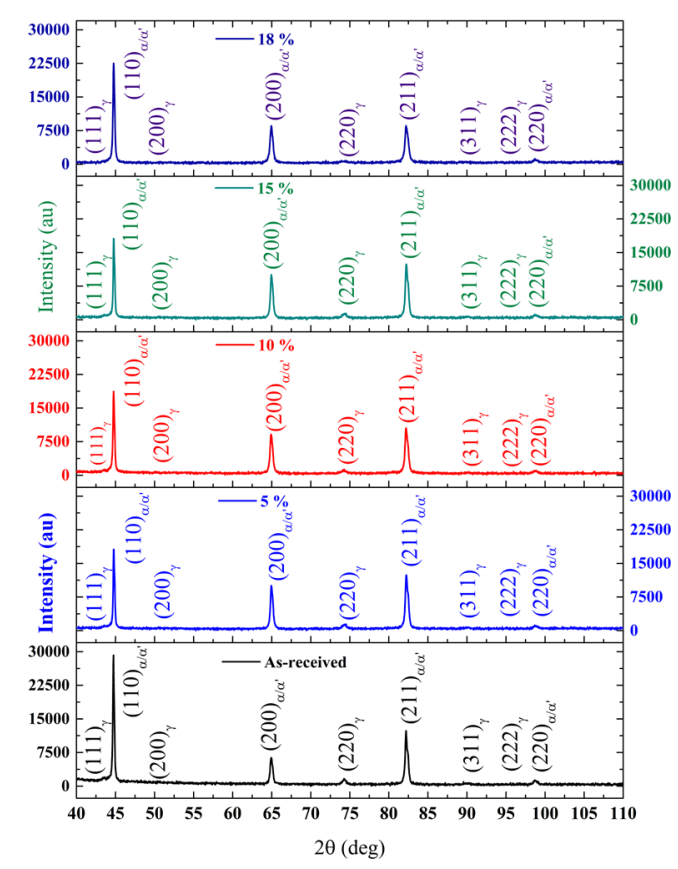

Figure 5. X-ray diffractogram patterns of TRIP780 steel sheet determined from the as-received condition and increasing pre-strain levels in uniaxial tensile loading.

displayed by the instantaneous strain-hardening exponent $\mathrm{n}=\mathrm{d}(\ln \sigma) / \mathrm{d}(\ln \varepsilon)$ which is plotted using the true-stress and the true plastic-strain data. The variation of the $n$-value with the true plastic-strain obtained for the TRIP780 steel is plotted in Figure 7(b) with the work-hardening behavior of a DP800 steel grade ${ }^{14}$ having a similar yield stress to tensile strength ratio (YS/TS) equal to 0.53 in comparison to 0.46 for the TRIP780 steel. It is worthwhile to observe that the strain-hardening exponent of the TRIP-aided steel gradually increases up to a maximum of $5 \%$ of true plastic-strain and then decreases slowly. This work-hardening behavior reveals that the SIMT effect in the evaluated TRIP780 steel was predominant at early stages of plastic strain, which is consistent with the results of both RA and transformed martensite volume fractions, shown in Figures 6(a) and 6(b). Conversely, the DP800 steel presents a faster strainhardening rate up to a maximum at the beginning stage of the plastic deformation $(\sim 1.5 \%)$ followed by a rapid decrease of the strain-hardening exponent. Previous works reported the two-stage work-hardening of DP steels ${ }^{18,19}$ relating the source of the initial higher strain-hardening exponent to the plastic deformation of the ferrite matrix whereas in the second stage both ferrite (soft) and martensite (hard) and or bainite phases are plastically deformed.

\subsection{Void analysis}

The RA behavior of the investigated TRIP780 steel through uniaxial tensile tests performed with a very low 


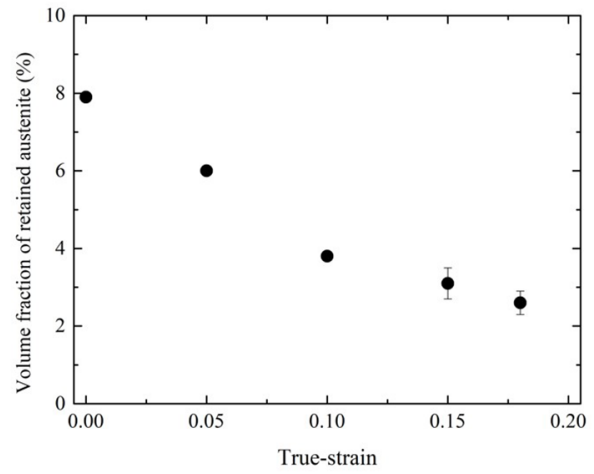

(a)

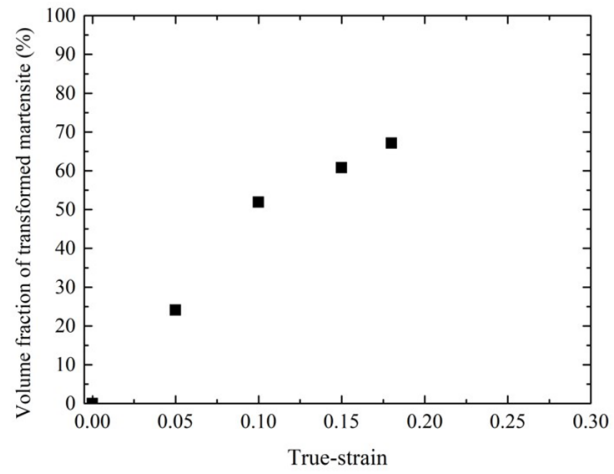

(b)

Figure 6. The volume fractions of (a) retained austenite and (b) strain-induced martensite determined from the as-received condition and increasing pre-strain levels in uniaxial tensile loading.

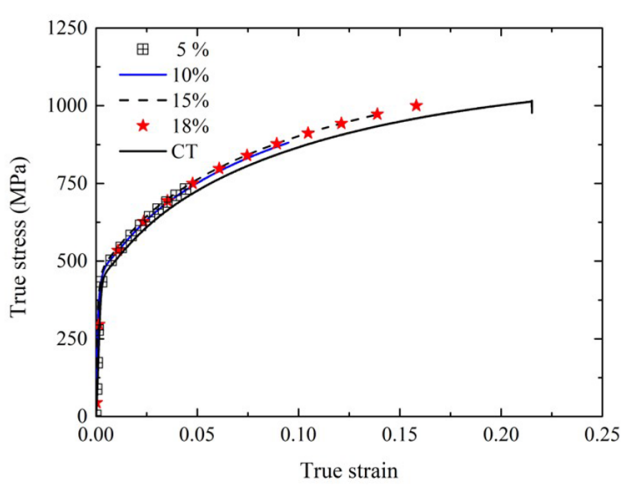

(a)

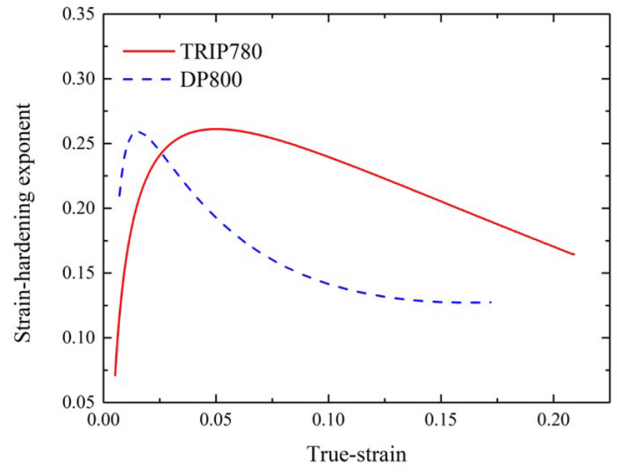

(b)

Figure 7. Uniaxial tensile mechanical behavior of the TRIP780 steel along the rolling direction: (a) interrupted and continuous tests and (b) instantaneous strain-hardening exponent compared with the plastic behavior of a similar AHSS grade.

strain-rate at room temperature revealed that the SIMT occurred predominantly in the uniform strain domain, as observed elsewhere ${ }^{20}$. The SIMT delays the nucleation of microvoids owing to the volumetric expansion and stress relaxation of the phases. However, as the RA volume fraction decreases or else the SIMT increase with the strain level, the microvoids gradually increase due to the mechanical mismatch between the soft ferrite matrix interfaces and the newly transformed hard martensite phase. At low prestraining levels, the formation of microvoids in TRIP-aided steels can be ascribed to the different mechanical behaviors of the existing and transformed phases and or to regions of stress concentrations.

The SEM image in Figure 8(a) was obtained from a parallel cross-section of the deformed sample at $5 \%$ of true-strain, namely, a plane along the sheet rolling (RD) and normal (ND) directions, in which it is possible to observe a microvoid formed between the regions of the ferrite matrix and the martensite (hard) phase that is at this stage is expected to deform in the elastic domain. Moreover, microvoids associated to the inclusions were also observed at both asreceived and samples deformed at lower straining level of 5\% true-strain. On the other hand, at intermediate and high strain levels the microvoids are nucleated around the inclusions, at the ferrite and martensite/retained austenite interface and the ferrite grain boundaries, as shown in the Figures 8(b) and $9(\mathrm{a}-\mathrm{b})$ corresponding to pre-straining levels of 10,15 and $18 \%$, respectively. Secondary electron images obtained from a TRIP steel under uniform straining in uniaxial tension indicated the coalescence of voids along grain boundaries aligned with the major tension axis ${ }^{21}$.

The quantitative void analysis in the TRIP780 steel sheet was done through binarization of several scanning electron microscopy images. Two sets of binarized images obtained from samples at parallel (ND - Normal Direction and RD - Rolling Direction) and transverse (ND - Normal Direction and TD - Transverse Direction) cross-sections of both as-received state and pre-strained conditions are 


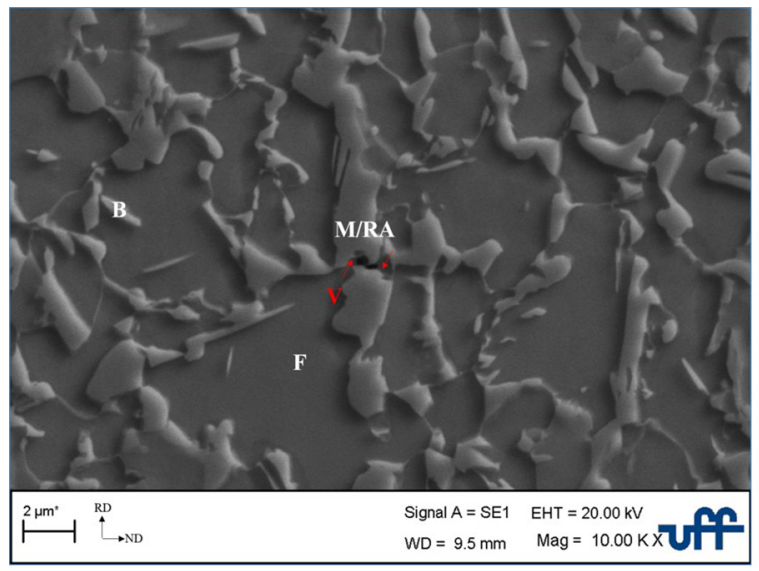

(a)

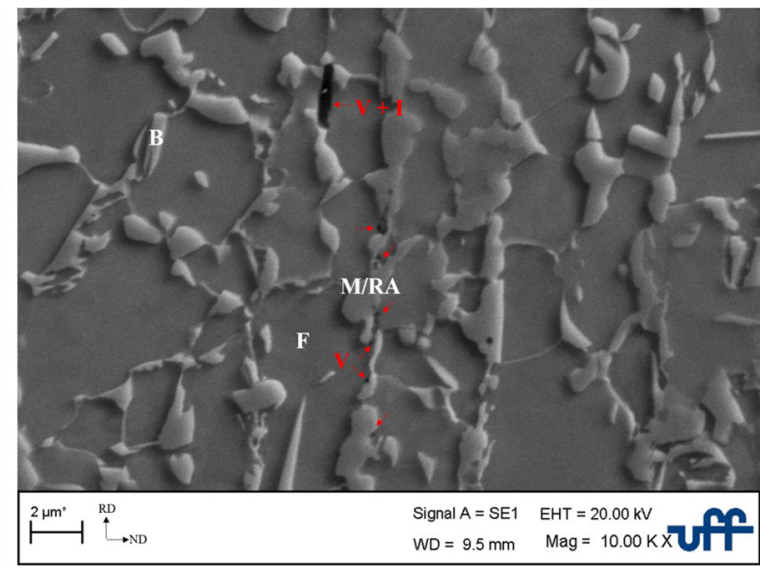

(b)

Figure 8. Scanning electron microscopy images obtained from the TRIP780 steel sheet uniaxial samples deformed at (a) 5\% (10000×) and (b) $10 \%(10000 \times)$ of total strain. The micrographs were taken at regions cut parallel to the sheet rolling direction, i.e., along the major strain axis. The letters B, F, M/RA, V and I designate ferrite, martensite/retained austenite, void and inclusion, respectively.

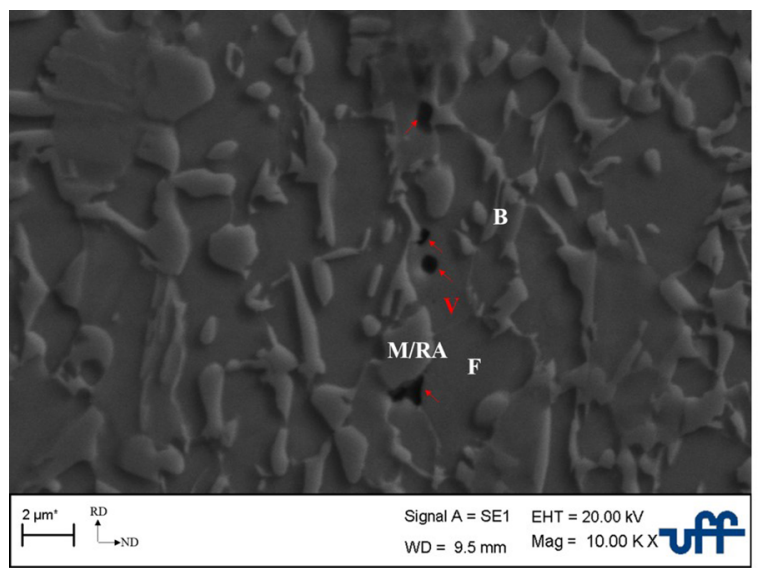

(a)

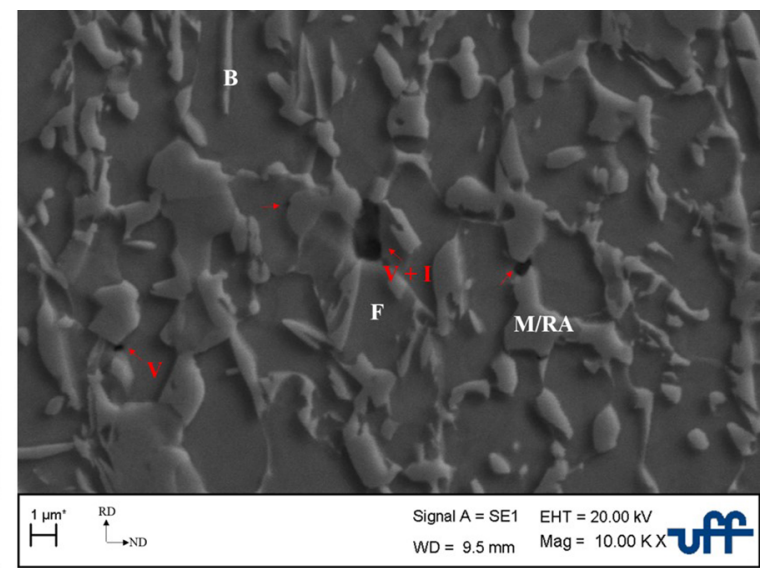

(b)

Figure 9. Scanning electron microscopy images obtained from the TRIP780 steel sheet uniaxial samples deformed at (a) $15 \%$ (10000×) and (b) $18 \%(10000 \times)$ of total strain. The micrographs were taken at regions cut parallel to the sheet rolling direction, i.e., along the major strain axis. The letters B, F, M/RA, V and I designate ferrite, martensite/retained austenite, void and inclusion, respectively.

shown in Figure 10. To determine the prevalent mechanisms of microvoids formation in the TRIP780 steel sheet, the digital image analysis provided the quantification of the void area fraction ( $\Sigma$ Void area/Total area $\times 100 \%$ ), void density (Void number per $\left.\mu \mathrm{m}^{2} \times 1,000\right)$, mean void size $(\Sigma$ Void area/Void number) and void aspect ratio (Mean void length/Mean void width).

The quantitative results obtained along the parallel and transverse cross-sections for the measures of void density (VD), void area fraction (VAF), void aspect ratio (VAR) and mean void size (MVS) are shown in Figures 11 and 12. First, the void measures of VD, VAF and MVS showed a dependence upon the angular orientation of the analyzed cross-section of the samples, namely, parallel and transverse which are along the major and minor in-plane strains axes, respectively. At the parallel cross-section, the VD increased from the as-received condition up to $10 \%$ of uniaxial prestrain resulting from the nucleation of microvoids together with an increase of the VAF, which indicate the growth and coalescence of microvoids. In the same straining range, the MVS slightly changed suggesting that the nucleation, growth and coalescence of microvoids occurred uniformly without any apparent predominant mechanism. From 10 up to $18 \%$ strain, the VD along the parallel cross-section shown a rapid decrease whereas the VAF increased and the MVS abruptly raised indicating that the growth and coalescence mechanisms prevailed in the domain of the intermediate and large strains. Conversely, at the transverse cross-section the VD decreased and both VAF and MVS increased from the as-received state up to $10 \%$ of strain 

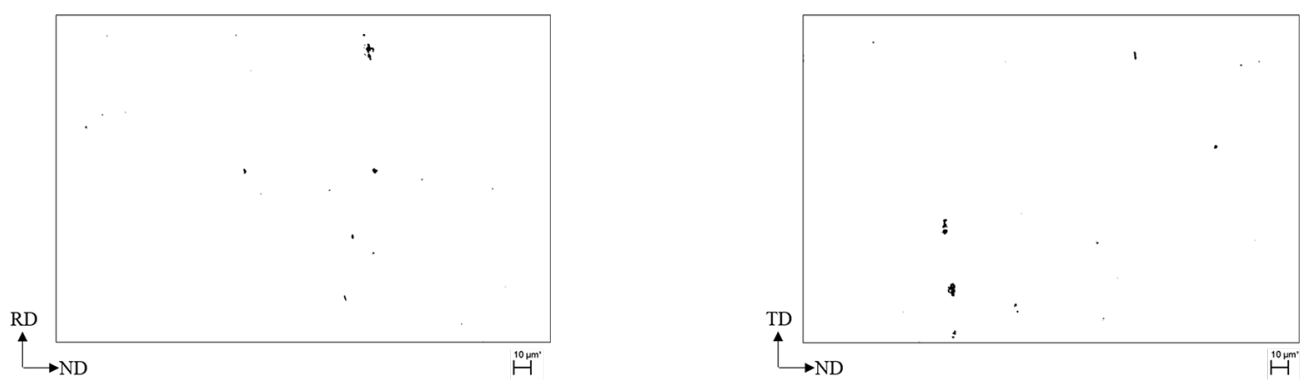

$18 \%$
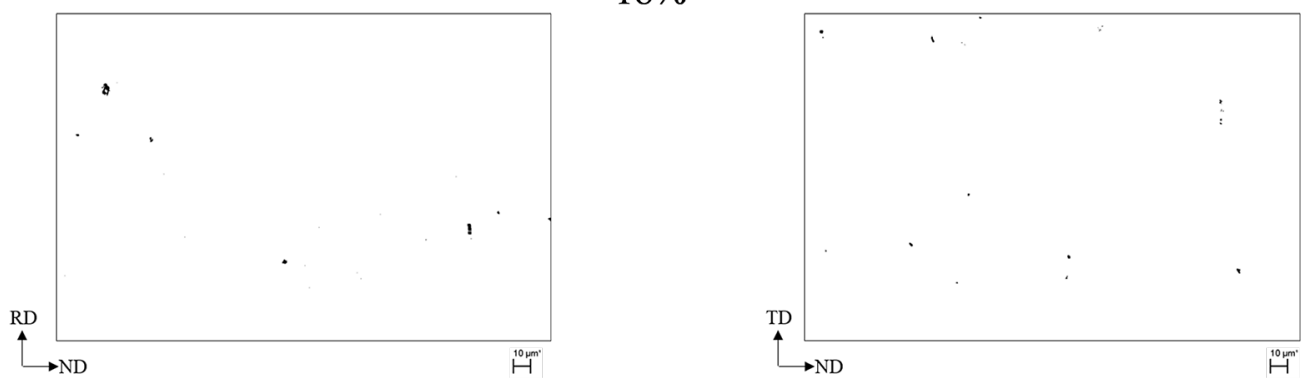

$15 \%$
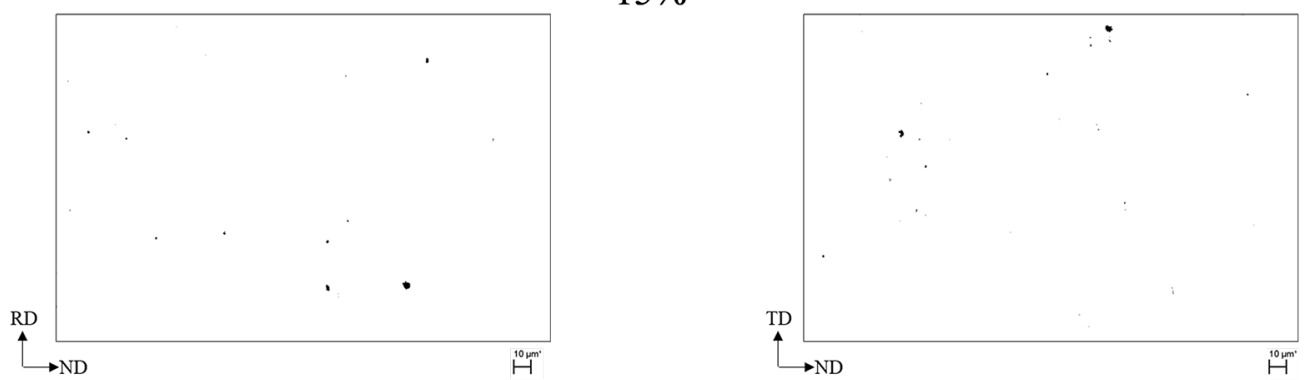

$10 \%$
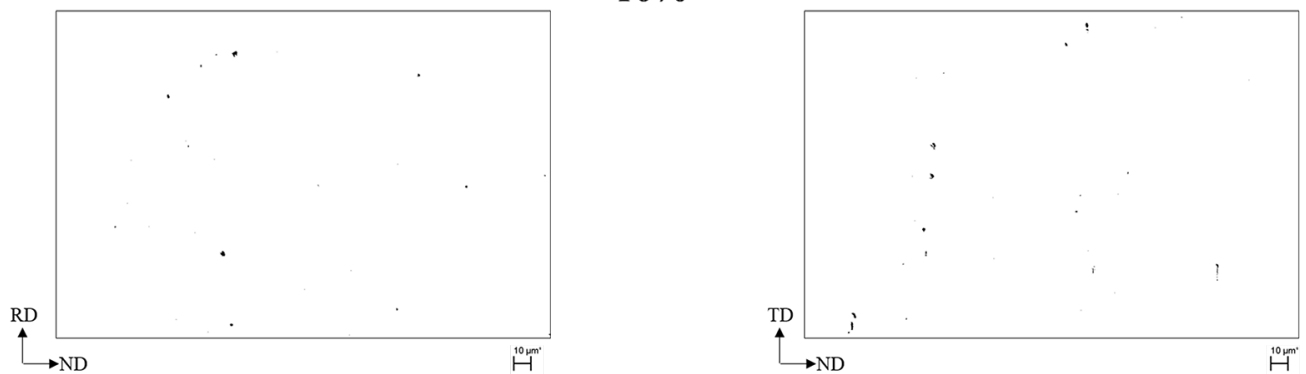

$5 \%$
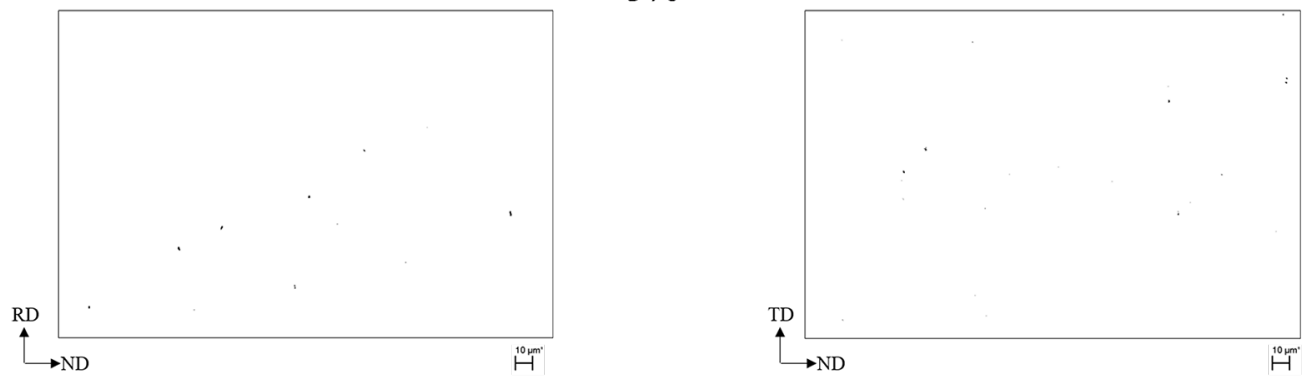

(a)

As-received

a)

(b)

Figure 10. Binarized images obtained from scanning electron micrographs used to define the microvoids measures in TRIP780 steel samples from as-received and pre-strained conditions: (a) parallel cross-section (ND - Normal Direction and RD - Rolling Direction) and (b) transverse cross-section (ND - Normal Direction and TD - Transverse Direction). 
characteristic of the growth and coalescence of microvoids along the minor in-plane strain axis. In the 10-15\% strain range, a slight increase in the VD is observed whereas the values of both VAF and MVS decreased suggesting the predominant nucleation of new microvoids revealed by an increase of the number of voids with small areas. In the larger straining range $15-18 \%$, both growth and coalescence of microvoids prevailed over the nucleation as can be seen from the reduction of the VD values together with an increase of both the VAF and MVS. Secondly, from the measured void aspect ratio (VAR) at both parallel and transverse cross-sections one can observe small variations for the as-received condition and pre-strained levels with VAR greater than 1.0 indicating that the microvoids along the major strain axis are prolate assuming an ellipsoidal shape. Lastly, the void analysis in the larger strain domain indicates that the growth and coalescence of microvoids prevailed at both parallel and transverse orientations.

\section{Conclusions}

In this work, TRIP780 steel sheets were investigated in both undeformed (as-received) and deformed (pre-strained in interrupted uniaxial tensile tests) to determine the dominant mechanisms responsible for nucleation, growth and coalescence of microvoids that trigger the damage process and, hence, governing the formability of this steel grade in sheet metal forming. The following main conclusions are summarized as:

1. Rapid changes in the retained austenite volume fraction occurred during the initial stages of the uniform strain domain with values varying from $7.9 \%$ corresponding to the as-received state up to $3.8 \%$ at $10 \%$ of true strain

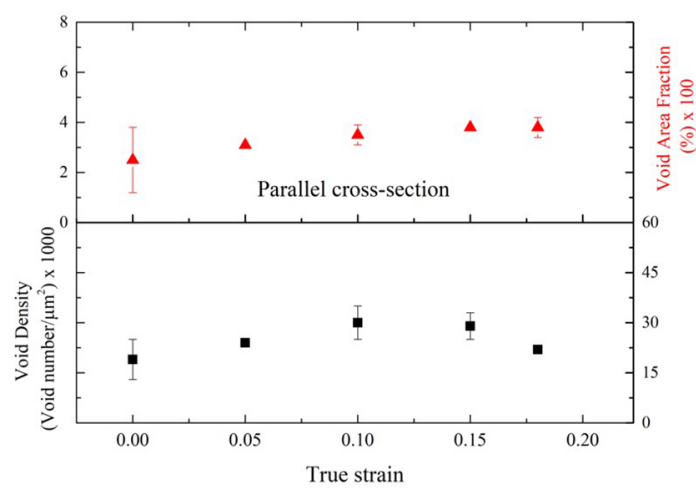

(a)

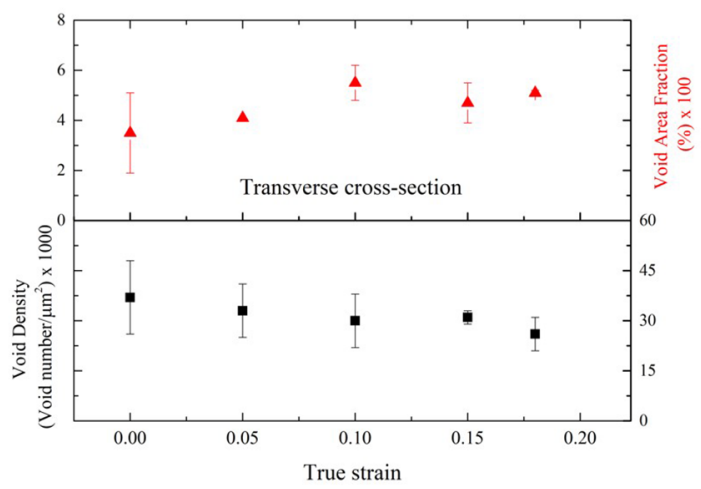

(b)

Figure 11. Void density and void area fraction results from the as-received condition and pre-straining levels in uniaxial tension: (a) parallel cross-section and (b) transverse cross-section.

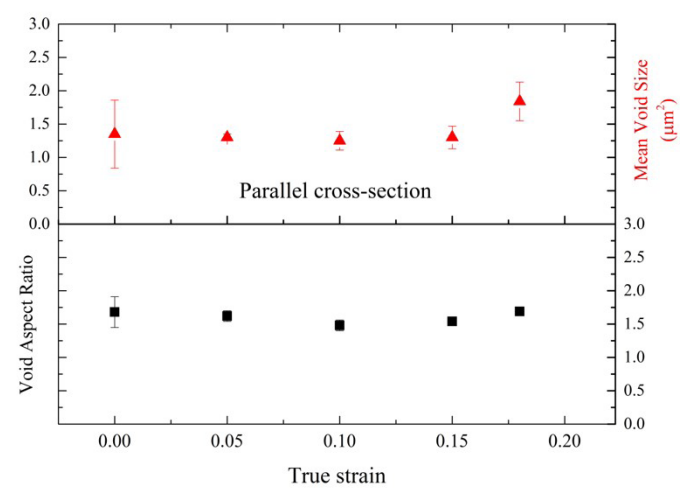

(a)

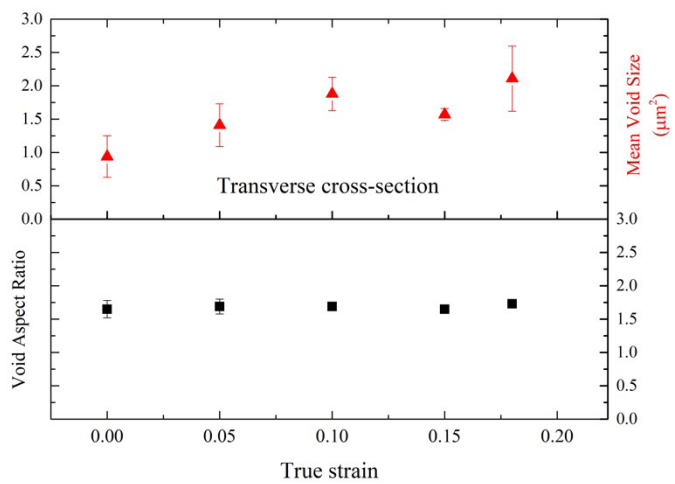

(b)

Figure 12. Void aspect ratio and mean void size results from the as-received condition and pre-straining levels in uniaxial tension: (a) parallel cross-section and (b) transverse cross-section. 
followed by a slow saturation in the strain-rage of 15 and $18 \%$ ending with $2.6 \%$.

2. The resulting volume fractions of strain-induced martensite transformed from the retained austenite values exhibited a rapid increase in the early stages of deformation up to $51.9 \%$ at an intermediate strain of $10 \%$ saturating at $18 \%$ with $67.1 \%$.

3. The instantaneous values of the strain-hardening exponent revealed the effects of the strain-induced martensite transformation enhancing the formability of the steel by a rapid work-hardening rate up to a maximum value at $5 \%$ of true-strain followed by a slow decrease in agreement with the observed behavior of both retained austenite and transformed martensite.

4. In the lower straining range of 5\% true-strain, prevailed the growth and coalescence of existing microvoids at the transverse cross-section and nucleation, growth and coalescence at the parallel cross-section (aligned with the major strain), indicating that the rapid observed strain-induced martensite transformation is responsible for delaying the nucleation of new voids. In this strain range, the microvoids were observed typically at the interface between the ferrite and martensite/ austenite constituents and around the inclusions.

5. In the intermediate and larger straining levels, the nucleation of microvoids prevailed in the transverse crosssection between 10 and $15 \%$ true-strain followed by growth and coalescence whereas at the parallel cross-section the mechanisms of growth and coalescence predominated from 10 up to $18 \%$. The microvoids were also observed at the interfaces with either inclusions and newly formed martensite as well as at the ferrite matrix.

\section{Acknowledgments}

The authors greatly acknowledge ArcelorMittal Vega (Brazil) for supplying the TRIP780 steel sheets. B.C. Castanheira and G. O. Nascimentos acknowledge CAPES/ DS program for granting the M.Sc. scholarships. L.P. Moreira acknowledges Brazilian agencies for supporting this work via research projects (FAPERJ E26- 211.760/2015 and CNPq 305194/2015-1). G.A.A. Santiago acknowledges the PIBIC/ UFF program research grant.

\section{References}

1. Liu L, He B, Huang M. The role of transformation-induced plasticity in the development of advanced high strength steels. Advanced Engineering Materials. 2018;20(6):1-17.

2. Aydin H, Essadiqui E, Jung IH, Yue S. Development of 3rd generation AHSS with medium Mn content alloying compositions. Materials Science and Engineering: A. 2013;564:501-508.

3. Speer JG, Edmonds DV, Rizzo FC, Matlock DK. Partitioning of carbon from supersaturated plates of ferrite, with application to steel processing and fundamentals of the bainite transformation.
Current Opinion in Solid State and Materials Science. 2004;8:219-237.

4. Caballero FG, Allain S, Puerta-Velásquez JD, Garcia-Mateo C. Exploring carbide-free bainitic structures for hot dip galvanizing products. ISIJ International. 2013;53(7):1253-1259.

5. Schmitt JH, Iung T. New developments of advanced high-strength steels for automotive applications. Comptes Rendus Physique. 2018;19(8):641-656.

6. Keeler S, Kimchi M, McConey PJ. Advanced High-Strength Steels Application Guidelines Version 6.0. Brussels, Bélgica: WorldAutoSteel; 2017.

7. Bleck W, Papaefthymiou S, Frehn A. Microstructure and tensile properties in dual phase and trip steels. Steel Research International. 2004;75(11):704-710.

8. Kim H, Lee J, Barlat F, Kim D, Lee MG. Experiment and modeling to investigate the effect of stress state, strain and temperature on martensitic phase transformation in TRIP-assisted steel. Acta Materialia. 2015;97:435-444.

9. Msolli S, Martiny M, Cardoso MC, Moreira LP, Mercier S, Molinari A. Numerical modeling of the deformation of AISI 304L using a tangent additive Mori-Tanaka homogenization scheme: Application to sheet metal forming. Journal of Materials Processing Technology. 2016;235:187-205.

10. Samek L, De Moor E, Penning J, De Cooman BC. Influence of alloying elements on the kinetics of strain-induced martensitic nucleation in low-alloy multiphase high-strength steels. Metallurgical and Materials Transactions: A. 2006;37(1):109-124.

11. Bleck W, Guo X, Ma Y. The TRIP effect and its application in cold formable sheet steels. Steel Research International. 2017;88(10):1700218.

12. Japanese Industrial Standard (JIS). Z-2201 - Test pieces for tensile test for metallic materials. Tokyo: Japanese Standards Association; 1998.

13. American Society for Testing and Materials (ASTM). E56202 - Standard test method for determining volume fraction by systematic manual point count. West Conshohocken, PA: ASTM International; 2003.

14. Santos RO, Silveira LB, Moreira LP, Cardoso MC, Silva FRF, Paula AS, et al. Damage identification parameters of dualphase 600-800 steels based on experimental void analysis and finite element simulations. Journal of Materials Research and Technology. 2019;8:644-659.

15. American Society for Testing and Materials (ASTM). E1245-03 - Standard practice for determining the inclusion or secondphase constituent content of metals by automatic image. West Conshohocken, PA: ASTM International; 2016.

16. Jacques PJ, Furnémont Q, Lani F, Pardoen T, Delannay F. Multiscale mechanics of TRIP-assisted multiphase steels: I. Characterization and mechanical testing. Acta Materialia. 2007;55(11):3681-3693.

17. Gnäupel-Herold T, Creuziger A. Diffraction study of the retained austenite content in TRIP steels. Materials Science and Engineering: A. 2011;528:3594-3600. 
18. Karimi MM, Kheirandish SH. Comparison of work hardening behaviour of ferritic-bainitic and ferritic-martensitic dual phase steels. Steel Research International. 2009;80(2):160-164.

19. Zuo X, Chen Y, Wang M. Study on microstructures and work hardening behavior of ferrite-martensite dual-phase steels with high-content martensite. Materials Research. 2012;15(6):915-921.
20. Wang W, Guo B, Ji Y, He C, Wei X. The study on the threshold strain of microvoid formation in TRIP steels during tensile deformation. Materials Science and Engineering: A. 2012;546:272-278.

21. Uthaisangsuk V, Prahl U, Bleck W. Modelling of damage and failure in multiphase high strength DP and TRIP steels. Engineering Fracture Mechanics. 2011;78(3):469-486. 